\title{
Alfabetização de idosos e adultos ou leitura e escrita?
}

\author{
Maria Hermínia Lage Fernandes Laffin \\ Universidade Federal de Santa Catarina, Brasil
}

Resumo

Apresento a análise de um processo de escolarização e letramento com idosos e adultos no Núcleo de Estudos da Terceira Idade/UFSC, no período de 2007 a 2011, em parceria com a rede municipal de ensino. Discuto o direito à garantia de profissionais habilitados na educação de idosos e adultos, condições adequadas, tanto na estrutura física como de materiais didáticos. Mediante um estudo a partir de perspectivas sociológicas e antropológicas dos processos educativos escolares em particular, neste texto analiso alguns elementos referentes ao curso, intitulado "Leitura e escrita", e também sobre os sujeitos que o frequentam e o debate sobre letramento de idosos e adultos. Como contribuições teóricas ao estudo foram fundamentais os trabalhos de Charlot (2000), Louro (1997), Menezes (2005), Soares (2000), Paiva (1997) e Sartori (2010). Como principais resultados relaciono um conjunto de elementos marcados pelas categorias gênero, questão geracional e necessidades financeiras de um grupo de sujeitos em busca de espaços de direitos e de inserção social.

Palavras-chave

Educação de idosos e adultos; Processos educativos; Direitos; Gênero

\section{Introdução}

Este trabalho tem como objetivo analisar questões referentes à intencionalidade dos sujeitos idosos/adultos ao procurarem a escolarização: a 
busca e a constituição de uma relação com o saber do mundo letrado, uma vez que vivem numa sociedade que valoriza práticas de uso da escrita e do conhecimento sistematizado. Tal problematização emerge a partir de ações de ensino, pesquisa e extensão, envolvendo um trabalho de escolarização junto a idosos e adultos no contexto da Universidade Federal de Santa Catarina, por intermédio do Núcleo de Estudos da Terceira Idade NETI ${ }^{1}$,UFSC e do Centro de Ciências da Educação. O trabalho teve início em 2007, a partir do diagnóstico realizado por esse Núcleo de que em seus projetos havia a necessidade de atender a uma parcela da população em processos educativos de demanda social e de escolarização.

$\mathrm{Na}$ proposta inicial deveriam e inicialmente atuaram como professores do curso educadoras voluntárias, com curso de monitoria em gerontologia realizado no próprio Núcleo, como forma de inserção social desses educadores, também da terceira idade. Esta questão nos traz essa importante dimensão, mas também o problema de que essas pessoas atuavam como voluntárias no projeto, não havendo formas de prover o seu trabalho, nem dispunham de tempos permanentes para a continuidade. Cabe considerar também a questão do direito à educação por parte de adultos e idosos, garantindo profissionais habilitados e condições adequadas, tanto na estrutura física como de materiais didáticos que atendam às suas particularidades.

Nesse contexto, as ações de pesquisa realizadas e situadas neste texto tomam suas análises em perspectivas sociológicas e antropológicas, considerando os processos educativos escolares e de letramento de idosos e adultos.

\section{Tecendo o fio desta história: da parceria com educadores voluntários a professores da rede de ensino - a questão do direito}

Pensar a questão do direito dos processos educativos de jovens, adultos e idosos é lembrar que esses direitos vêm sendo objeto de lutas, no sentido de que esses processos possam passar a não mais se configurar como um "desinteresse" por parte do Estado, mas se efetivem no âmbito das políticas públicas com a garantia de sua oferta por parte do Estado. Outra 
questão refere-se à noção de direito à educação como parte constitutiva de políticas públicas de Estado. O percurso dos debates sobre a escolaridade obrigatória remete-nos à Emenda Constitucional Brasileira de 1969, que modifica a redação da Constituição de 1967, a qual situa, pela primeira vez, o Estado com o dever de ofertar a educação, e se configura também na Constituição Federal de 1988, ao estabelecer que "a educação é direito de todos e dever do Estado e da família" e ainda que é o "ensino fundamental obrigatório e gratuito, inclusive sua oferta garantida para todos os que a ele não tiveram acesso na idade própria". Segundo Sartori (2010), mediante esse quadro legal, as leis advindas, seja em nível federal, estadual ou municipal, não podem se contrapor à constituição, mas devem trabalhar na lógica da garantia desse direito.

Sartori (2010, p. 73) questiona ainda sobre a garantia do direito ao Ensino Fundamental gratuito a todos, independente da idade, e lembra, ao citar as diretrizes de Educação de Jovens e Adultos (EJA), que os alunos e as alunas de EJA devem conhecer e fazer valer essa prerrogativa. Questiona ainda: jovens, adultos e idosos conhecem este direito? Valem-se dele? Em algum momento conhecemos alguém que se valeu do mesmo? Quantos alunos e alunas não conseguem, muitas vezes, concluir o Ensino Fundamental por falta de turmas, quando este direito deveria ser assegurado pelas instituições públicas no ato da procura por vaga? Igualmente, essa noção de direito também requer que os estudantes jovens e adultos tenham profissionais habilitados e condições na estrutura física das instituições públicas de modo atender a suas particularidades.

Retomando o fio da história do curso: em 2007, o grupo de voluntários educadores era formado por quinze pessoas (um homem e quatorze mulheres), todos com curso superior ou magistério, alguns com experiência em processos educativos. Além disso, o mais importante: eram pessoas que atuavam com a terceira idade, envolvidos em movimentos e organizações populares, e que se propuseram a seguir uma linha pedagógica coerente com a aprendizagem de adultos. Dos quinze, nove educadoras assumiram turmas no projeto, organizadas em grupos de três por turma.

O curso efetivamente começou no segundo semestre de 2007, com 35 alunos. A matrícula final em 2007 foi de 30 estudantes, pois 4 precisaram sair e 1 faleceu. Em 2008 houve a abertura de uma quarta turma e mais 17 
pessoas se matricularam no curso, totalizando 47 educandos/as. Porém, ocorreram 18 desistências ao longo do semestre, alguns por motivos pessoais e outros por questões financeiras, pois alguns tinham menos de 65 anos e precisavam arcar com os custos de transporte para frequentar as aulas. Nesse momento, ainda não contavam com auxílio-transporte. Após recesso de férias, em Agosto de 2008, oito novos estudantes foram inseridos, totalizando 37 .

Com o entendimento de que o processo educativo, para esses estudantes, passa a se constituir como um direito, e que, portanto, possibilitava/exigia também outros direitos, a partir de 2009 procuramos a parceria da Secretaria Municipal de Florianópolis, a qual passou a incluir esses estudantes em seu cadastro, a fornecer a equipe docente para 0 trabalho, além de alimentação escolar e auxílio-transporte. No entanto, alguns educadores voluntários mantêm até hoje o seu trabalho, no acompanhamento das turmas, e contamos também com bolsistas do curso de Pedagogia.

Em 2009, já com a parceria com a Secretaria Municipal, mantiveramse três turmas, cuja matrícula final foi de 30 estudantes. Nos anos de 2010 e 2011, para que nossos estudantes tivessem direito à continuidade de estudos, foram organizadas duas turmas: uma de primeiro segmento, com cerca de 20 estudantes, e outra de segundo, com 15 (Quadro 1). Atualmente, na turma de | Segmento, atua uma professora pedagoga, e na primeira fase do || Segmento, numa abordagem interdisciplinar, trabalham cinco professores das áreas de ensino. O I Segmento tem três encontros semanais de quatro horas e o Il tem três encontros com a mesma duração.

\begin{tabular}{ccccc}
\hline Ano & $\begin{array}{c}\text { Matrículas } \\
\text { iniciais }\end{array}$ & $\begin{array}{c}\text { Novas } \\
\text { matrículas }\end{array}$ & Evadidos & $\begin{array}{c}\text { Matrículas } \\
\text { finais }\end{array}$ \\
\hline $\mathbf{2 0 0 7}$ & 30 & & 4 & 26 \\
$\mathbf{2 0 0 8}$ & 30 & 25 & 12 & 37 \\
$\mathbf{2 0 0 9}$ & 30 & & 3 & 27 \\
$\mathbf{2 0 1 0}$ & 35 & - & 2 & 34 \\
$\mathbf{2 0 1 1}$ & 34 & 2 & 3 & 35 \\
\hline
\end{tabular}

Quadro 1 


\section{A proposta do curso "Leitura e escrita" para idosos e adultos}

Assumimos uma concepção de educação de idosos e adultos baseada no pensamento de Vygotsky, para quem as relações do homem com o mundo são fundamentalmente mediadas por instrumentos e signos. O sujeito humano, em suas ações, cria instrumentos e signos para transformar a natureza e a si mesmo, construindo a cultura.

Segundo estudos de vários autores - tais como Vygotsky (1993), Kohl de Oliveira (1983), Oliveira (1999) e Luria (1990), entre outros -, adolescentes, idosos e adultos diferem das crianças no processo de aprender, não pelo modo como compreendem o objeto de conhecimento, mas pelo modo como suas mentes trabalham para alcançá-lo.

É preciso considerar a idade adulta não como fase estável e sem transformações psicológicas, mas de continuidade de desenvolvimento psicológico. Suas experiências e circunstâncias culturais, históricas e sociais propiciam situações de aprendizagem promovendo o desenvolvimento psicológico (Durante, 1998, p. 19).

Desse modo, o desafio de processos educativos de idosos e adultos consiste em articular o conhecimento já apropriado pelos sujeitos nas suas atividades cotidianas com as novas aprendizagens escolares e com as formas sistematizadas de resolver os problemas. Pensa-se, então, em desenvolver um ensino significativo e não somente funcional, ou restritamente utilitário. Significativo por trabalhar com conteúdos úteis e motivadores, voltados para o desenvolvimento de um grande número de relações com outros conteúdos e, portanto, que favorecem o desenvolvimento cognitivo dos sujeitos, ampliando as possibilidades de leitura do real e de melhor criticar, decidir suas ações e agir.

Faz-se necessário desenvolver um ensino voltado para a compreensão e, para tanto, é preciso trabalhar coletivamente para a construção de um projeto educativo de idosos e adultos que busque tais dimensões, além de repensar de que modo lidar com o conhecimento e quais conteúdos são relevantes na educação de idosos e adultos, o que pode gerar várias polêmicas. Pensar as questões curriculares implica em definir a concepção educativa que se quer, para quem e para quê. Numa visão progressista e emancipatória, as práticas educativas constroem seu currículo 
em processo e não abrem mão do tempo histórico em que vivem os educandos.

Nenhuma ação educativa se dá sobre o vazio. Para ensinar são necessários conteúdos, que não dispensam a forma como devem ser trabalhados. Paulo Freire alerta para o fato de que, ao se discutir conteúdos, é fundamental buscar revelar sua natureza política e ideológica. Logo, faz-se necessário analisar que

(...) o currículo pode promover: tanto pelo que ele claramente revela, quanto pelas formas sutis pelas quais ele se oculta. $\mathrm{O}$ que o currículo revela diz respeito ao conhecimento escolar que o constitui, selecionado, particular e arbitrariamente, em um universo muito mais amplo de possibilidades (Paiva, 1997, p. 4).

Deve-se buscar o conhecimento que prepare homens e mulheres para o seu tempo, ampliando a sua capacidade de agir na construção do novo, compreendendo e criticando o que vem sendo produzido. Os conteúdos do currículo de um projeto educativo para idosos e adultos deverão trazer as temáticas sociais para a sala de aula, como conteúdos sistematizados, capazes de favorecer a visão interdisciplinar que permita a compreensão da totalidade concreta. Entende-se a necessidade de valorizar a intencionalidade dos sujeitos na constituição da sua relação com o saber ao procurarem a escolarização, uma vez que vivem numa sociedade que valoriza práticas de uso da escrita e do conhecimento sistematizado. Dessa forma, o sujeito se vê inserido num contexto, afirmando Charlot (2000) que isso significa:

(...) ver-se submetido à obrigação de aprender. Aprender para construir-se, em um triplo processo de "hominização", de singularização, de socialização. Aprender para viver com outros homens com quem o mundo é partilhado. Aprender para apropriar-se do mundo, de uma parte desse mundo, e para participar da construção de um mundo pré-existente. Aprender em uma história que é, ao mesmo tempo, profundamente minha, no que tem de única, mas que me escapa por toda a parte. Nascer, aprender, é entrar em um conjunto de relações de processos que constituem um sistema de sentido, onde se diz quem eu sou, que é o mundo, quem são os outros (Charlot, 2000, p. 53).

Para esse pesquisador, essa é uma condição que faz do filho do homem um sujeito, sempre em interação, partilhando o mundo com os outros. Para isso, faz-se necessário que o sujeito "se aproprie do mundo e construa a si mesmo, se eduque e seja educado" (Charlot, 2000, p. 49). Um conceito fundamental levantado por esse pesquisador refere-se à noção de devir do 
sujeito humano. Para ele, o sujeito humano não é, mas "deve ser; para tal, deve ser educado por aqueles que suprem sua fraqueza inicial e deve educarse, 'tornar-se por si mesmo"' (idem, p. 52).

O sujeito constrói sua própria história singular, inscrita na história do gênero humano, e dessa forma ocupa um lugar social, no qual exerce uma atividade em que ele produz e se produz a si mesmo. Mas Charlot (idem, $\mathrm{p}$. 54) alerta que essa produção só é possível pela mediação do outro e com sua ajuda. Para esse processo se efetivar, é necessário que o sujeito tenha essa intencionalidade, ou seja, que consinta e colabore nesse processo. Para tanto, o sujeito precisa encontrar também mediações e condições objetivas no mundo que oportunizem e possibilitem esse processo educativo. A partir disso, pensa-se uma escola de idosos e adultos em que se produzam novos saberes e heranças culturais no sentido de promover maior compreensão sobre o mundo em que se vive.

No sentido destas reflexões, entende-se a necessidade de um conjunto de ações educativas para uma política integrada de educação de idosos e adultos que possa propiciar a apropriação de conhecimentos, pois isso é assumir a própria função permanente da educação de adultos.

\section{Idosos e adultos: sujeitos da ação pedagógica}

O novo cenário populacional brasileiro tem mostrado um número crescente de idosos, os quais buscam novas alternativas de inserção social, atividades e oportunidades de aprendizagem. Entre as possibilidades encontradas estão os programas de alfabetização, que oferecem uma oportunidade de combate ao preconceito, uma vez que o idoso acredita que a educação é um caminho para a inclusão social.

Um grande problema para o idoso hoje é sua adaptação às exigências do mundo moderno. Isto se deve, em parte, à deficiência educacional desta geração, de uma época em que freqüentar escola era um privilégio de poucos. Por isto, o alto índice de analfabetismo, que atinge 5,1 milhões de idosos no país. Existe ainda o analfabetismo funcional, que corresponde aos indivíduos que têm menos de 4 anos de estudo. Os números do Censo mostram que $59,4 \%$ dos idosos responsáveis pelos domicílios são analfabetos funcionais (IBGE Teen - Brasil, 2008).

Esse dado reitera análises do IBGE (Brasil, 2008 e 2010) que mostram que, segundo o censo de 2000, a população de idosos representa um 
contingente de quase 15 milhões de pessoas com 60 anos ou mais de idade ( $8,6 \%$ da população brasileira). Há um aumento no índice de envelhecimento: em 2008, para cada grupo de 100 crianças de 0 a 14 anos, existiam 24,7 idosos de 65 anos ou mais; as projeções indicam que, em 2050, para cada 100 crianças de 0 a 14 anos existirão 172,7 idosos (Censo IBGE - Brasil, 2010).

Por um lado, se a perspectiva de vida aumentou, por outro, certos direitos constitucionais foram garantidos: em 1991 tínhamos uma taxa de $40,1 \%$ de pessoas consideradas analfabetas na faixa etária de 50 anos ou mais; em 2000, essa taxa foi de $48,7 \%$; e foi de $57,5 \%$ em 2010. Em forma de números absolutos, contamos ainda cerca de 5,1 milhões de idosos analfabetos no País. As mulheres são maioria: 8,9 milhões (62,4\%) das idosas são responsáveis pelos domicílios e têm, em média, 69 anos de idade e 3,4 anos de estudo (Figura 1). Em relação ao gênero, os homens continuam sendo, proporcionalmente, mais alfabetizados do que as mulheres $(67,7 \%$ contra $62,6 \%$, respectivamente), já que até os anos 60 tinham mais acesso à escola do que as mulheres.

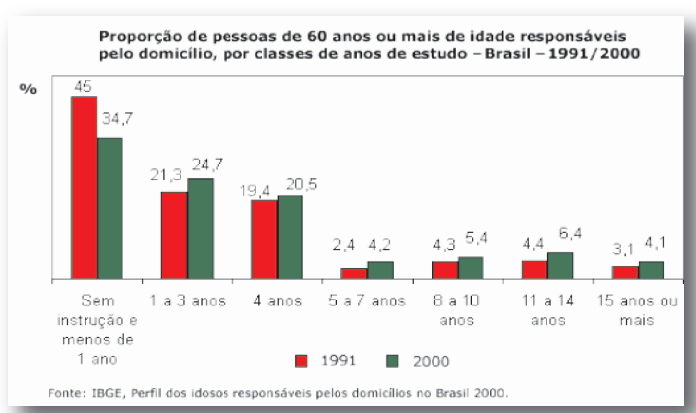

Figura 1

Fonte: www.ibge.gov.br/ibgeteen/datas/idoso/perfil_idosos.html (acesso em 20/02/2012)

Desse contexto macro, ao visualizarmos o perfil dos sujeitos com os quais trabalhamos no Curso de Leitura e Escrita analisado, contamos até o momento, em nosso curso, com um total de 159 matrículas, sendo que desse total alguns estudantes estão no curso desde 2007. Em relação à faixa etária no período de 2007 a 2008, constata-se que, no que respeita à questão geracional, de um total de 51 estudantes, a idade variava de 30 a 89 anos, em 
sua maioria entre 60 e 69 anos (Quadro 2). Esses dados trazem-nos indicativos importantes em relação à questão geracional para pensarmos os processos pedagógicos com estudantes idosos e adultos. Também relevante para a análise é o fato de que a maioria dos estudantes são mulheres, ou seja, constituem $75 \%$ do total.

\begin{tabular}{|l|c|c|c|c|c|c|}
\hline \multicolumn{7}{|c|}{ Faixa etária dos estudantes do Curso de Leitura e Escrita } \\
\hline Idade & $\begin{array}{c}30 \text { a } 39 \\
\text { anos }\end{array}$ & $\begin{array}{c}40 \text { a } 49 \\
\text { anos }\end{array}$ & $\begin{array}{c}50 \text { a } 59 \\
\text { anos }\end{array}$ & $\begin{array}{c}60 \text { a } 69 \\
\text { anos }\end{array}$ & $\begin{array}{c}70 \text { a } 79 \\
\text { anos }\end{array}$ & $\begin{array}{c}80 \text { a } 89 \\
\text { anos }\end{array}$ \\
\hline $\begin{array}{l}\text { Número de } \\
\text { estudantes }\end{array}$ & 1 & 5 & 14 & 20 & 9 & 2 \\
\hline
\end{tabular}

\section{Quadro 2}

Fonte: Dados da pesquisa (2009/2010)

Quando se pensa a questão de quem são hoje essas mulheres adultas e idosas, precisamos compreender o contexto cultural e histórico em que elas, enquanto meninas, abandonaram a escola ou em que, por algum motivo, não a frequentaram. A pesquisadora Guacira Louro (2001), ao estudar os processos educativos de meninas e meninos no começo do século passado, particularmente aqueles das camadas populares, adverte que seria uma simplificação entender sua educação de modo universal dentro da sociedade:

Evidentemente as divisões de classe, etnia e raça tinham um papel importante na determinação das formas de educação utilizadas para transformar as crianças em mulheres e homens. (...) As diferentes origens dos "trabalhadores livres" também implicavam diferentes práticas educativas. (...) Suas diferentes formas de inserção na produção e na sociedade brasileiras (como operários fabris, lavradores, ou pequenos proprietários) também teriam consequências nos processos educativos (Louro, 2001, pp. 444-445).

Mas em relação às meninas, Louro (2001, p. 445) adverte ainda:

No entanto, não se pode esquecer que, de um modo geral, as meninas das camadas populares estavam, desde muito cedo, envolvidas nas tarefas domésticas, no trabalho da roça, no cuidado dos irmãos menores, e que essas atribuições tinham prioridade sobre qualquer forma de educação escolarizada para elas.

Esse fato é reiterado não só pelo dado quantitativo, mas pelo que afirmam as estudantes ao serem entrevistadas: 
É, eu parei de estudar no quarto ano chorando, porque eu gostava muito de estudar, porque sou filha única, e a minha mãe ia trabalhar e eu não podia estudar. Eu chorei, chorei, mas falavam que mulher não precisava estudar, que era pra homem, e não sei mais o quê, e que eu não iria trabalhar fora. A minha vontade era estudar eu gostava, tirava notas ótimas na aula, daí me casei nova e fui criando meus filhos, perdi meus avós, perdi minha mãe, nove anos faz que perdi meu marido, e meu sonho era estudar, e até que o ano passado comecei a estudar (Maria, 68 anos - Dados da pesquisa, 2009/2010).

A maior contradição, no caso de Maria, situa-se na idade adulta, quando ela passa a trabalhar em uma escola como auxiliar de limpeza, com crianças, e continua sem poder ter acesso a processos de escolarização: "Eu trabalhava com crianças na escola particular (...), no primário... Cuidava das crianças durante a entrada e saída, limpava o colégio" (Maria, 68 anos Dados da pesquisa, 2009/2010)

Temos ainda outros casos nos depoimentos de Loni e Paula:

- Quais os principais motivos que levaram a se afastar da escola naquela época?

- É, eu fiz até o terceiro ano do primário. É que a minha mãe trabalhava num sítio, quer dizer, morava, era dela, e aí ela não botava na escola, não tinha razão pra não por lá!

- Mas a senhora tinha que ajudar em casa?

- Não, eu não fazia nada, a minha mãe trabalhava fora fazia comida pra nós (Loni, 66 anos - Dados da pesquisa, 2009/2010).

Eu queria continuar estudando, mas como eu reprovei na quinta-série, meu pai disse para minha mãe me tirar da escola porque eu era uma burra e nunca ia aprender (Paula, 56 anos - Dados da pesquisa, 2009/2010).

Percebem-se, nessas falas, indícios de uma concepção culturalmente naturalizada pelas famílias de uma não necessidade das mulheres frequentarem a escola, noção que nos leva a refletir sobre os papéis sociais que mulheres e homens acabam assumindo em função do que se considera como válido em determinados momentos históricos. Tal noção também se refere ao que se pode observar relativamente aos modos como determinados grupos sociais são representados ou o quanto eles exercitam como relações de dominação e vivem o poder na vida social. São diferentes representações das imagens de ser homem e ser mulher em nossa cultura.

Menezes (2005), ao estudar a participação feminina em turmas da Educação de Jovens e Adultos e as implicações das relações de gênero no processo de escolarização de alunas da EJA, faz as seguintes análises 
acerca dos fatores que contribuíram para o abandono escolar dos estudantes pesquisados quando os sujeitos eram mais jovens: a) a questão econômica, com a busca de complementos à renda familiar por meio do emprego doméstico; b) outros trabalhos na adolescência; c) desestímulo/desinteresse pela escola (estavam voltadas a outras experiências próprias da adolescência, como os namoros, a "turma", as festas, a espera do casamento, etc.); d) casamento como meta; e) o cuidado de seus filhos.

Esta nossa pesquisa apresenta ainda dados novos e diferentes àqueles analisados por Menezes (2005), particularmente indicados por Maria, Loni e Paula com as afirmações de que "mulher não precisava estudar, que era pra homem", "e aí ela não botava na escola, não tinha razão pra não por lá" e "disse para minha mãe me tirar da escola porque eu era uma burra e nunca ia aprender". Uma das possibilidades de análise desse dado em relação àqueles apontados por Menezes talvez esteja situada na questão geracional, pois Menezes, em sua pesquisa, trabalhou com um público um pouco mais jovem (com idade de 30 a 39 anos). Já esta pesquisa situa sujeitos com um pouco mais de idade e, no caso dos depoimentos acima, os quais efetivamente poderíamos caracterizar na categoria de idosos (56 a 69 anos), o que, portanto, acaba trazendo certas particularidades também na construção de concepções da construção de gênero dessas mulheres e de seus processos educativos.

Já quando indagamos aos estudantes homens adultos e idosos sobre os motivos do seu afastamento da escola quando meninos, obtivemos os seguintes depoimentos:

Eu estudei muito pouco, fui muito pouco à aula, era na igreja. Eu tinha um cunhado de que era muito bom né, eu tinha que arrumar as coisas, ir pra roça, ia pra cidade vender batata e entregar as roupas que a mãe lavava roupa pra fora. Cheguei a lavar roupa, fazer as mamadeiras pros sobrinhos, eu fiz tudo isso aí. Como eu te disse foi por causa da doença do meu cunhado, por que ele era doente e não podia ajudar, aí eu não podia deixar minha irmã e meu sobrinho passar fome, então eu tinha que ajudar na roça, tinha que lavar, isso quando tinha 8 a 10 anos, que é que eu podia fazer, desde pequeno tive que ajudar meus pais, e a minha mãe me deixava lá na avó, e a gente não gastava, e a minha irmã fazia o que era da casa da lida, e aí morava assim, quando tinha coisa pra comer, comia, quando não tinha passava fome. E aí ia pra roça, arrancava batata para comer, cozinhava, por que não tinha (Luís, 66 anos Dados da Pesquisa, 2009/2010).

Estudei só até a quarta série, pois naquela época nós tínhamos que trabalhar. Parei na quarta série e fiquei anos e anos, mais de vinte anos sem estudar. 
Voltei agora faz um ano e pouco, muita coisa esquecida. Na época tinha que trabalhar, os pais eram linha dura, assim, né, já trabalhei em supermercado, naquela época, hoje de menor não pode trabalhar acho (Vilson, 43 anos Dados da Pesquisa, 2009/2010).

Temos ainda uma noção do ser mulher mais ligada aos trabalhos manuais, voltada à esfera privada, e da construção de ser homem voltada ao espaço do público, mas ambas com relações voltadas a situações de exclusão social. Situar tais posições nos faz refletir sobre como as pessoas se movem no mundo e, portanto, tais relações precisam ser problematizadas, sobretudo quando falamos de relações hierarquizadas e excludentes. Olhar e analisar estas questões significa tirá-las do silêncio, questionar papéis préestabelecidos e afirmar que estes papéis podem e devem ser recusados pelos próprios sujeitos das práticas escolares, no sentido da busca da igualdade social.

Perante a análise dos elementos da pesquisa de Menezes (2005) e dos dados desta pesquisa, temos um conjunto marcado pelas categorias 'gênero' e 'necessidades financeiras', que configuram um grupo de sujeitos em busca de espaços de direito e de inserção social que anteriormente the foram negados, e que no Núcleo de Estudos da Terceira Idade encontram um espaço de pertencimento e de reconhecimento, ao afirmar:

(...) para a outra escola eu não queria ir, aqui eles conversam, explicam, eles têm paciência, para quem não sabe elas vão na carteira e assim, com muita paciência, é uma beleza, não posso reclamar! (Joana, 54 anos - Dados da Pesquisa, 2009-2010).

\section{Sobre alfabetização, leituras e escritas: dos processos de apropriação de sujeitos idosos e adultos}

Para situar processos educativos com sujeitos idosos e adultos, gostaria ainda de refletir teoricamente sobre um caso vivido logo no início do curso, quando o grupo de estudantes recebeu uma bolsa, tipo modelo de congresso, em que colocamos um cartaz (figura 2) como uma identificação do curso, o qual era também a capa do livro de textos de apoio. No cartaz, além da identificação da Universidade e do Núcleo da Terceira Idade, estava escrito no centro, com letras bem salientes, "Alfabetização de adultos", modo como se intitulava o curso inicialmente. O que chamou a atenção é que muitos dos 
estudantes idosos, logo no início, começaram a tirar o cartaz da bolsa, ou mesmo a virá-lo para o lado de dentro da mesma, quando a usavam. Este episódio nos fez refletir sobre o fato de nossos estudantes idosos e adultos, ao se verem inseridos em uma sociedade que valoriza o saber letrado (e que viram em nosso curso uma possibilidade de participação), ao tirarem o cartaz da bolsa estavam afirmando que não precisavam ser reconhecidos/rotulados pela sua distância em relação a esse saber. Ou seja, a intencionalidade dos sujeitos em busca de uma relação com o saber é marcada por uma "obrigação social de aprender", uma vez que vivemos em uma sociedade que valoriza a cultura letrada, na qual o termo 'analfabeto' assume um significado eminentemente pejorativo, definindo o sujeito pela sua distância com relação ao saber letrado valorizado socialmente, e não pelos conhecimentos que domina. Os estudantes idosos e adultos estavam na universidade exatamente em busca de diminuir essa distância, e não para lhe darmos uma "etiqueta", identificando-os como sujeitos em alfabetização.

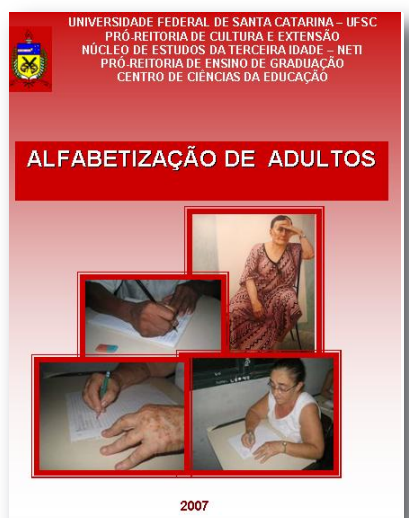

Figura 2 - Cartaz de identificação do Curso em 2007

Fonte: Dados da pesquisa (2009/2010)

Desse modo, em 2008 o nome do curso passou a ser "Curso de Leitura e Escrita para Idosos e Adultos". Tal postura foi assumida pela análise, que se capta na reação dos estudantes, do que significa assumir uma determinada valorização pessoal e social em que o sujeito que afirma/se sente participar 
de um curso de leitura e escrita no contexto de uma universidade é diferente da valorização que assume aquele que diz/se sente participar de um curso de alfabetização em uma sociedade em que ser analfabeto ainda carrega um significado tão pesado. Esta mudança não é só uma questão de semântica, mas efetivamente de concepção e de reconhecimento dos sujeitos e de suas particularidades e seus direitos.

Ainda, o termo 'analfabeto' remete para além da representação social de quem não sabe ler e escrever, mas também daquele que, sabendo, é incapaz de compreender ou redigir um texto com determinadas características. Desse modo, à medida que a sociedade vai se tornando cada vez mais centrada no saber escrito, não basta apenas aprender a ler e escrever: é necessário incorporar a prática da leitura e da escrita. Para nomear esse novo fenômeno surgiu a palavra 'letramento'.

O termo 'letramento' surge de literacy, que significa a condição de ser letrado. É, pois, o adjetivo que caracteriza a pessoa que domina a leitura e a escrita e designa o estado ou a condição daquele que sabe ler e escrever e faz uso competente e frequente da leitura e da escrita. Para alguns autores, como Soares (1998) e Kleiman (1995), ser letrado é ir além de ser alfabetizado: é tornar-se cognitivamente diferente, ou seja, o sujeito se apropria de novas formas de pensar e interagir com esse mundo letrado. Entende-se o letramento como um conjunto de práticas sociais de uso do conhecimento escrito, ampliam-se as agências de letramento para além da escola, abrangendo a família, a igreja, o trabalho, as organizações populares, etc. (Soares, 1998). Assim, pensar práticas de letramento exige considerar a sua dimensão social, ou seja, pensar os significados da escrita para os determinados grupos sociais. Já o pesquisador Jean Foucambert (1994) aponta o analfabetismo como o desconhecimento das técnicas de utilização da escrita, enquanto o iletrismo se caracteriza pela falta de familiaridade com o mundo de utilização da escrita, uma exclusão em relação ao todo ou a parte desse modo de comunicação.

Refletindo a partir desses conceitos, cada um de nós é iletrado em diversos campos. Quando esses campos são muitos, se observa, até mesmo entre aqueles que foram alfabetizados, uma volta ao analfabetismo e ao esquecimento das técnicas básicas que permitem utilizar a escrita. Ainda Foucambert (1994, p. 18) afirma que: 
Outrora, o analfabetismo resultava da ausência de escolarização. Hoje, aparece como conseqüência do iletrismo. Como o funcionamento social exclui dos processos de decisão e poder entre 50 e $70 \%$ dos "cidadãos", estes são excluídos também dos motivos para encontrar na escrita o que ela tem de específico. Seu não saber técnico revela-se como uma resposta equilibrada ao seu estatuto social de não-leitor.

Ao pensarmos as práticas escolares de letramento junto a sujeitos idosos, é preciso salientar que, nesse processo, recebemos estudantes que, mesmo não tendo frequentado a escola, ou quando pouco escolarizados, participam de atividades interativas com o mundo letrado, o que os torna portadores de conhecimentos sobre a escrita, apresentando muitas vezes, na linguagem oral, características da linguagem escrita. Portanto, os sujeitos idosos não alfabetizados não desconhecem o sistema da escrita e sua função, mas suas concepções sobre ele são decorrentes das condições da relação estabelecida, nas suas histórias de vida, com esse conjunto de saberes, ou seja, das possibilidades diferenciadas de interação com a língua escrita. Desse modo, é primordial refletir sobre as práticas pedagógicas na Educação de Jovens e Adultos e os aspectos de poder implicados nesse processo, para quem está aprendendo a ler e escrever.

\section{Práticas escolares de letramento e práticas sociais de letramento}

Perante as reflexões acima, é possível inferir que, no processo de escolarização de idosos e adultos, a realidade da escola e do contexto social permite que tanto professores como alunos venham construindo e encontrando objetivos e significados para a aprendizagem e seus processos de letramento.

Ao situar o processo de letramento como um processo construído social e culturalmente, dimensiona-se a continuidade deste texto mediante falas de sujeitos adultos em processos de escolarização no seu processo de letramento. Essas falas sinalizam o que significa, para esses sujeitos, se sentirem inseridos ou excluídos do chamado processo de letramento.

No texto presente na Figura 3 (abaixo), apesar de não se tratar de uma pessoa idosa, destaca-se a dimensão que proporciona o saber fazer 'ler e escrever' como um meio de inserção/inclusão do sujeito no processo de 
letramento, enquanto forma de participação coletiva. Junto a este texto, a professora fez o registro do percurso de aprendizagem da estudante após um mês de aula: "A aluna escreveu 'Agora é melhor já sei ler e escrever na escola!'. Está começando a ler e escrever agora. Disse que agora não é mais analfabeta" (Professora Lúcia). Analisa-se, nesta fala, a dimensão do que significa o fato de saber 'ler e escrever' como um meio de inserção do sujeito no processo de letramento. Indica o quanto significa, para a aluna, a apropriação de alguns elementos desse código letrado, os quais Ihe permitem afirmar-se participante de um conjunto de referências comuns a um grupo letrado, e, portanto, dele sentir-se sujeito e autorizar-se a dizer "faço parte deste grupo".

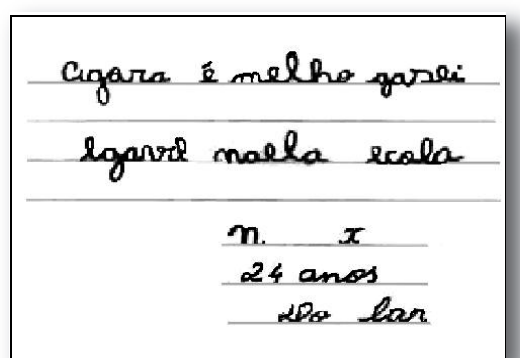

Figura 3 - Texto original da estudante de Educação de Jovens e Adultos

Fonte: Dados de Pesquisa (2005/2006)

Por outro lado, considerar essa dimensão da apropriação de saberes remete a pensarmos as práticas escolares de adultos em uma concepção não necessariamente utilitarista, mas de uma preocupação efetiva com o conhecimento e com os saberes valorizados socialmente. Segundo Ribeiro (1999), realmente a questão da funcionalidade das aprendizagens está inscrita nas práticas de escolarização de jovens e adultos como um fator de motivação para os sujeitos que voltam à escola. No entanto, a autora reafirma que essa dimensão não deve comprometer outros processos que dão sentido à escolarização, pois

A orientação do ensino para exigências do mundo do trabalho ou qualquer outro contexto específico de vivência não deve implicar a renúncia ao distanciamento crítico em relação à realidade imediata. A oportunidade de descolar-se da ação 
imediata para poder dedicar-se à elaboração do próprio conhecimento é uma das especificidades da aprendizagem escolar que outras instituições sociais dificilmente podem promover com a mesma intensidade. Certamente é fundamental desenvolver pesquisas que esclareçam quais competências e saberes são exigidos pelos contextos de trabalho (Manfredi 1998) e por outras dimensões da vida cotidiana (Ribeiro 1999). Entretanto, também é de extrema relevância a análise de como saberes e competências relacionados aos contextos existenciais dos jovens e adultos trabalhadores poderiam ser abordados pedagogicamente de modo a fazer avançar sua capacidade crítica, criatividade e autonomia, e não meramente como capacitação para tarefas específicas, sem maior relevância cognitiva ou atitudinal (Ribeiro, 1999, p. 7).

Também Paulo Freire (1987, p. 102) aponta que a tarefa do educador dialógico é levantar do universo temático dos alunos, recolhido mediante rigorosa investigação de seus problemas e visões da realidade, elementos que possibilitem devolver essa temática aos educandos como questões problematizadoras, para que possam fazer a crítica dessa realidade. Freire (1980, p. 25) alerta que essas questões problematizadoras possibilitam a aproximação crítica da realidade. Segundo ele,

Num primeiro momento a realidade não se dá aos homens como objeto cognoscível por sua consciência crítica. Noutros termos, na aproximação espontânea que o homem faz do mundo, a posição normal fundamental não é uma posição crítica, mas uma posição ingênua. (...) A conscientização implica, pois, que ultrapassemos a esfera espontânea da apreensão da realidade, para chegarmos a uma esfera crítica na qual a realidade se dá como objeto cognoscivel e na qual o homem assume uma posição epistemológica (Freire, 1980, p. 26).

Já em outro conjunto de falas dos estudantes idosos, capta-se a sua denúncia do quanto se identificavam como excluídos das práticas de letramento ao iniciarem processos de escolarização:

Quando eu vim eu não sabia quase nada. Hoje, então eu me sinto sabida. Sei escrever mais e ler. Porque a pessoa que não sabe ler é um rio sem água (Josefa, 50 anos).

No começo não sabia nada. Agora já sei um pouco ler e escrever. Quem não sabe ler é cego (Olívia, 65 anos).

"Quem não sabe ler é cego", "(...) a pessoa que não sabe ler é um rio sem água", "Disse que agora não é mais analfabeta". Destaca-se, nos depoimentos, o quanto os sujeitos se sentem distantes do saber ao serem confrontados com a exigência de um determinado saber valorizado 
socialmente: o saber exigido nas práticas de letramento. Dirigir o olhar para essa questão é perceber o sujeito que procura o processo de letramento como inscrito nas práticas sociais da história humana.

Essas falas remetem também a dados indicados pelos docentes ao desenvolverem práticas escolares de letramento, principalmente sobre o modo como os sujeitos adultos se identificam ao se inserirem nos processos de escolarização, que se refere ao fato de que têm muita insegurança, de que precisam melhorar a própria autoestima. Nessa perspectiva, ao analisarmos o que apontam estudantes e docentes em relação à desvalorização que os alunos idosos e adultos fazem de si, precisamos lembrar que essa é uma imagem construída socialmente nas próprias relações desses sujeitos com o mundo, construída na sua relação de distância com este "saber letrado" e com a valorização social desse saber. Desse modo, essa desvalorização não está no sujeito em si, mas é uma imagem que constrói na distância em que ele se percebe cotidianamente com relação as suas vivências com esse saber. Charlot (2000, pp. 17-18) evidencia que tal relação é marcada por uma percepção de ausência e de diferença ao lidar com dificuldade nestas situações que impõem o uso desse saber, construindo assim "uma imagem desvalorizada de si".

Vale lembrar que, enquanto o sujeito desenvolve ou não ações de aprendizagens com relação a determinados conhecimentos, ele aprende também sobre suas potencialidades, suas capacidades e dificuldades de lidar com o saber e modos de enfrentar tais dificuldades. Desse modo, segundo Charlot (idem, p. 34), pensarmos o sujeito da escolarização na sua "relação com o saber letrado é estudar esse sujeito enquanto confrontado com a necessidade de aprender e a presença de 'saber' no mundo". Nessa relação com o saber, em que constrói "uma imagem desvalorizada de si", precisamos considerar o que afirma Bernard Charlot:

(...) o sujeito epistêmico é o sujeito afetivo e relacional, definido por sentimentos e emoções em situação e em ato; isto é - para não recorrer a algo inapreensível - o sujeito como sistema de condutas relacionais, como conjunto de processos psíquicos implementados nas relações com os outros e consigo mesmo (Charlot, 2000, p. 70).

Também Paulo Freire (1980, p. 73), ao falar da marginalidade dos sujeitos, apontada, muitas vezes, em visões equivocadas sobre a situação do 
sujeito "dito analfabeto", afirmava que essa visão dava-se em função do não reconhecimento e da ausência de análise da realidade histórica, social, cultural e econômica em que esse sujeito encontrava-se inserido. Sobre essa identificação de que o sujeito estaria "à margem", "fora de", Freire interroga: se ele está à margem no caso do saber letrado, quem é o autor desse movimento que o "põe de fora"? É o próprio sujeito marginalizado que decide se colocar à margem? Essa marginalidade consiste em opção do sujeito? Ora, citando o próprio Paulo Freire:

Se a marginalidade não é opção, o homem marginalizado tem sido excluído do sistema social e é mantido fora dele, quer dizer, é objeto de violência. O homem marginalizado não é "um ser fora de". É, ao contrário, um "ser no interior de", em uma estrutura social em relação de dependência para com os que chamamos falsamente de seres autônomos. (...) Na realidade, estes homens analfabetos ou não - não são marginalizados. Repetimos: não estão "fora de", são seres "para o outro". Logo, a solução de seu problema não é converteremse em "seres no interior de", mas em homens que se libertam, porque não são homens à margem da estrutura, mas homens oprimidos no interior desta mesma estrutura que é responsável por esta mesma dependência. Não há outro caminho para a humanização - a sua própria e a dos outros -, a não ser uma autêntica transformação da estrutura desumanizante (Freire, 1980, pp. 7475).

Em seu livro Pedagogia do oprimido (1987, p. 50), Freire aponta que, na sua relação com o mundo, os sujeitos oprimidos quase sempre não se percebem como quem "conhece", como quem tem um conhecimento, ainda que este seja no nível da pura doxa, descrendo de si mesmos, assumindo assim uma característica de autodesvalia. Essa noção de desvalia percebida pelo sujeito é, portanto, construída na sua relação com o mundo, com o outro e com os saberes do mundo letrado. Segundo Paulo Freire (idem, pp. 53-54), para que, nos processos educativos dialógicos e emancipadores, possamos contribuir para a construção de outra autoimagem dos sujeitos é fundamental que, acima de tudo, "creiamos nos homens oprimidos. Que os vejamos como capazes de pensar certo também. (...) A ação política junto aos oprimidos tem de ser, no fundo 'ação cultural' para a liberdade, por isto mesmo, ação com eles". Dessa forma, para Freire, a sensação de dependência emocional do sujeito constitui-se fruto de uma situação objetiva de dominação em que esse se acha, e que acaba gerando também sua visão inautêntica do mundo.

Estas reflexões são extremamente relevantes, pois no cotidiano, principalmente da Educação de Adultos, ouvimos constantemente esses 
alertas de que primeiro de tudo é preciso trabalhar a autoestima dos educandos. O problema com esta expressão é que, semanticamente, 'auto' remete a "por si próprio", "de si mesmo"; já 'estima' indica "sentimento da importância ou do valor de alguém ou de alguma coisa; apreço, consideração, respeito" (Holanda, 1975, p. 162 e 582). Logo, o termo 'autoestima' nos leva a pensar o 'valor de si mesmo, considerado por si próprio'. Ora, nesse sentido, seria legitimar a visão de que o problema da distância do sujeito na sua relação com o saber estaria centrado no próprio sujeito, quando, na realidade, essa é, efetivamente, uma relação construída e inscrita nas práticas excludentes da história humana, já que

Sujeitos sócio-culturais são também seres concretos e plurais. São pessoas vivas e reais, existindo a partir de sua corporeidade e lugar social, a partir de sua condição de mulheres, homens, negros, brancos. Pertencem a diferentes raças e etnias. São crianças, jovens ou de mais idade, adeptos de variadas crenças e costumes. Têm desejos, projetos e atribuem variadas significações às suas experiências e ao mundo. Para entendê-los, é necessário considerar esses seus atributos, sejam eles adscritos ou adquiridos, pois tudo isso matiza sua existência e condição (Teixeira, 1996, p. 185).

É nesse sentido que opto por tomar emprestada de Charlot a expressão "uma imagem desvalorizada que os sujeitos têm de si", no contexto das práticas de letramento e das relações sociais. Mas como estudantes idosos e adultos vêm representando essa relação com o mundo letrado? No próximo conjunto das falas de estudantes de educação de idosos e adultos, evidencia-se o que representa, para eles, participar do processo de letramento, como forma de uso da escrita, para se orientar no mundo, para entender-se, lendo ou escrevendo, descobrindo e visualizando alternativas e possibilidades de interação nas práticas de letramento:

Eu estou aprendendo muito mais do que eu já sabia. Eu espero aprender muito mais, pretendo continuar; com certeza chegarei lá (Paula, 56 anos).

Eu vim aprender a ler para poder preencher cheque, tenho dinheiro no banco e não posso assinar um cheque (Mariana, 43 anos).

Ah, eu vim aprender a ler para poder ler os bilhetes que estão nos bolsos do meu marido. Ele não queria! Ah, ah, ah! (Edna, 54 anos)

Eu, Santina Cilei da Rosa, autorizo a publicação da minha redação para xérox (Santina, 52 anos).

Este último depoimento, que se constituiu como texto escrito, é resultado da solicitação feita à professora da estudante Santina para que a 
aluna autorizasse publicar um texto seu. Segundo a professora, no dia seguinte a aluna Ihe entregou este pequeno texto, que marca precisamente a noção de autoria percebida pela própria estudante. É perceber-se como capaz de dizer, de escrever, de participar socialmente do mundo letrado. Capta-se a imagem de um sujeito que se situa com possibilidades de participar das práticas de letramento, que pode ler em e nas diferentes condições: no cotidiano, por prazer, por lazer. É interagir com a imprensa diária e usar a leitura para seguir instruções, dar apoio à memória, comunicarse com quem está ausente (Soares, 1998).

Sob este olhar do lugar da leitura e escrita, Foucambert afirma que, para aprender a ler e escrever, é necessário

(...) estar envolvido pelos escritos os mais variados, encontrá-los, ser testemunha de e associar-se à utilização que os outros fazem deles - quer se trate dos textos da escola, do ambiente, da imprensa, dos documentários das obras de ficção. Ou seja, é impossível tornar-se leitor sem essa contínua interação com um lugar onde as razões para ler são intensamente vividas mas é possível ser alfabetizado sem isso..." (Foucambert, 1994, p. 31).

Logo, as práticas sociais de letramento implicam trabalhar com os inúmeros textos veiculados na sociedade, desde poesias até formulários, receitas, placas de sinalização - o que pressupõe uma prática escolar que envolva a escrita da voz, do ouvido, do gesto, da imagem. É um processo rico de interação com as diversas formas da linguagem e dos signos.

Muitas vezes, na escola, propõe-se a produção de textos para ninguém ler, apenas para o educando demonstrar o que sabe ou não e para o/a professor/a corrigir. Contrapondo a isso, a organização e o ensino dos saberes escolares deverão ser realizados de modo a possibilitar uma aprendizagem contextualizada e significativa, uma vez que

(...) um saber só tem sentido e valor por referência às relações que supõe e produz com o mundo, consigo, com os outros. Os alunos para quem o saber tem, ao que parece, "um sentido e um valor como tal", são os que conferem um sentido e um valor ao saber-objeto sob sua forma substancializada; o que supõe relações de um tipo particular com o mundo, consigo e com os outros (Charlot, 2000, p. 64).

Pensa-se uma escola para e dos adultos e idosos, lugar em que se produzam outras relações com e do mundo letrado; uma escola que dê sentidos, significados e sabores a esses saberes, no sentido de promover maior compreensão sobre o mundo em que vivemos. Que estas reflexões 
acerca dos direitos de nossos adultos e idosos, como o caso do Curso de Leitura e Escrita apresentado, ao tecer suas próprias histórias de leituras e escritas, possam ajudar a tecer outras histórias com muitos idosos e adultos...

\section{Notas}

1 O Núcleo de Estudos da Terceira Idade (NETI) é um órgão vinculado ao Departamento de Projetos de Extensão da Pró-Reitoria de Pesquisa e Extensão da Universidade Federal de Santa Catarina. O NETI coloca o conhecimento da gerontologia à disposição da comunidade, desenvolvendo estudos e pesquisas, inserindo e promovendo as pessoas idosas no meio acadêmico, como sujeitos em transformação e agentes transformadores da sociedade.

\section{Referências}

Brasil (2008). Pesquisa nacional de amostra por domicílio. Rio de Janeiro: Instituto Brasileiro de Geografia e Estatística (IBGE).

Brasil (2010). Pesquisa nacional de amostra por domicílio. Rio de Janeiro: Instituto Brasileiro de Geografia e Estatística (IBGE).

Charlot, B. (2000). Da relação com o saber. Porto Alegre: Artes Médicas.

Durante, M. (1998). Alfabetização de adultos: Leitura e produção. Porto Alegre: Artes Médicas.

Foucambert, J. (1994). A leitura em questão. Porto Alegre: Artes Médicas.

Freire, P. (1980). Conscientização: Teoria e prática da libertação. São Paulo: Cortez e Moraes.

Freire, P. (1987). Pedagogia do oprimido. Rio de Janeiro: Paz e Terra.

Holanda, A. B. (1975). Dicionário da Língua Portuguesa. Ed. Nova Fronteira.

Kleiman, A. (Org.). (1995). Os significados do letramento. Campinas: Mercado de Letras.

Louro, G. L. (1997). Mulheres na sala de aula. In M. Del Priore (Org.), História das mulheres no Brasil ( $5^{\mathrm{a}}$ ed.) (pp. 443-481). São Paulo: Contexto.

Luria, A. R. (1990). Desenvolvimento cognitivo. São Paulo: Ícone.

Menezes, C. (2005). As relações de gênero no processo de escolarização de alunas da Educação de Jovens e Adultos (Monografia de especialização). UFPE.

Oliveira, M. K. (1983). Inteligência e vida cotidiana: Competências cognitivas de adultos de baixa renda. Cadernos de Pesquisa, 44, 45-54.

Oliveira, M. K. (1999). Jovens e adultos como sujeitos de conhecimento e aprendizagem. Revista Brasileira de Educação, 12, 59-73. 
Paiva, J. (1997). Que conteúdos dilemas na Educação de Jovens e Adultos. In Um salto para o futuro - Série Educação de Jovens e Adultos. Rio de Janeiro: Fundação Roquette Pinto.

Ribeiro, V. M. (1999). A formação de educadores e a constituição da Educação de Jovens e Adultos como campo pedagógico. Educação \& Sociedade, 20(68), pp. 184-201. Disponível em http://www.scielo.br/scielo.php?script=sci_arttext\&pid= S0101-73301999000300010\&Ing=en\&tIng=pt (acesso em 24 de maio de 2012).

Sartori, A. (2010). Desenvolvimento histórico das políticas públicas e educacionais em Educação de Jovens e Adultos na legislação nacional. In Educação de Jovens e Adultos na diversidade. UFSC, Núcleo de publicações do CED.

Soares, M. (1998) Letramento: Um tema em três gêneros. Belo Horizonte: Autêntica.

Teixeira, I. C. (1996) Os professores como sujeitos sócio-culturais. In J. C. Dayrell (Org.), Múltiplos olhares sobre educação e cultura. Belo Horizonte: UFMG.

Vygotsky, L. S. (1993). Pensamento e linguagem. São Paulo: Martins Fontes. 


\section{ADULT AND ELDERLY LITERACY EDUCATION OR JUST READING AND WRITING?}

\section{Abstract}

This paper presents an analysis of elderly and adults' literacy education at Núcleo de Estudos da Terceira Idade/UFSC (Elderly People Study Research Group/UFSC), between 2007 and 2010, undertaken in partnership with Florianopolis County Education Department. I discuss the right of elderly people and adults to competent professionals in schooling, appropriate study conditions and didactic materials, as well as adequate structural facilities. Starting with a study on the sociological and anthropological aspects of the educational processes at school, in this text I analyze some elements of the literacy course, and I also inquire people involved in it. As theoretical contributions that were fundamental to this study I must highlight the works of Charlot (2000), Louro (1997), Menezes (2005), Soares (2000), Paiva (1997) and Sartori (2010). As main results I stress a set of elements marked by gender categories, generation issues and the economic needs of a group of people searching for space and the right to social inclusion.

Keywords

Elderly and adults' schooling; Educational processes; Rights; Gender

\section{ALPHABÉTISATION DE PERSONNES AGÉES ET D'ADULTES OU LECTURE ET ÉCRITURE?}

\section{Résumé}

Je vous présente l'analyse d'un processus de scolarité de personnes agées et d'adultes au Núcleo de Estudos da Terceira Idade/UFSC (Centre d'Etudes du Troisième Age/UFSC), de 2007 à 2010, en partenariat avec le reseau d'enseignement de la municipalité. J'étudie le droit à la présence obligatoire de professionnels certifiés à l'enseignement de personnes agées et d'adultes, et aussi le droit aux conditions adéquates de la structure physique et des 
matériels didactiques.L'étude des perspectives sociologiques et anthropologiques des processus éducatifs, surtout scolaires, est à la base de l'analyse, dans ce texte, de quelques éléments relatifs au cours "Lecture et écriture", et aussi de l'analyse de l'alphabétisation et quelques caractéristiques des sujets qui le fréquentent. Les travaux de Charlot (2000), Louro (1997), Menezes (2005), Soares (2000), Paiva (1997) et Sartori (2010) ont été fondamentaux pour la base théorique. Les principaux résultats constituent un ensemble d'éléments dont font partie les catégories de genre, d'âge et de besoins financiers d'un groupe de personnes à la recherche d'espaces de droits et d'insertion sociale.

Mots-clé

Enseignement de personnes agées et d'adultes; Processus éducatifs; Droits; Genre

Recebido em Fevereiro/2011

Aceite para publicação em Julho/2012 